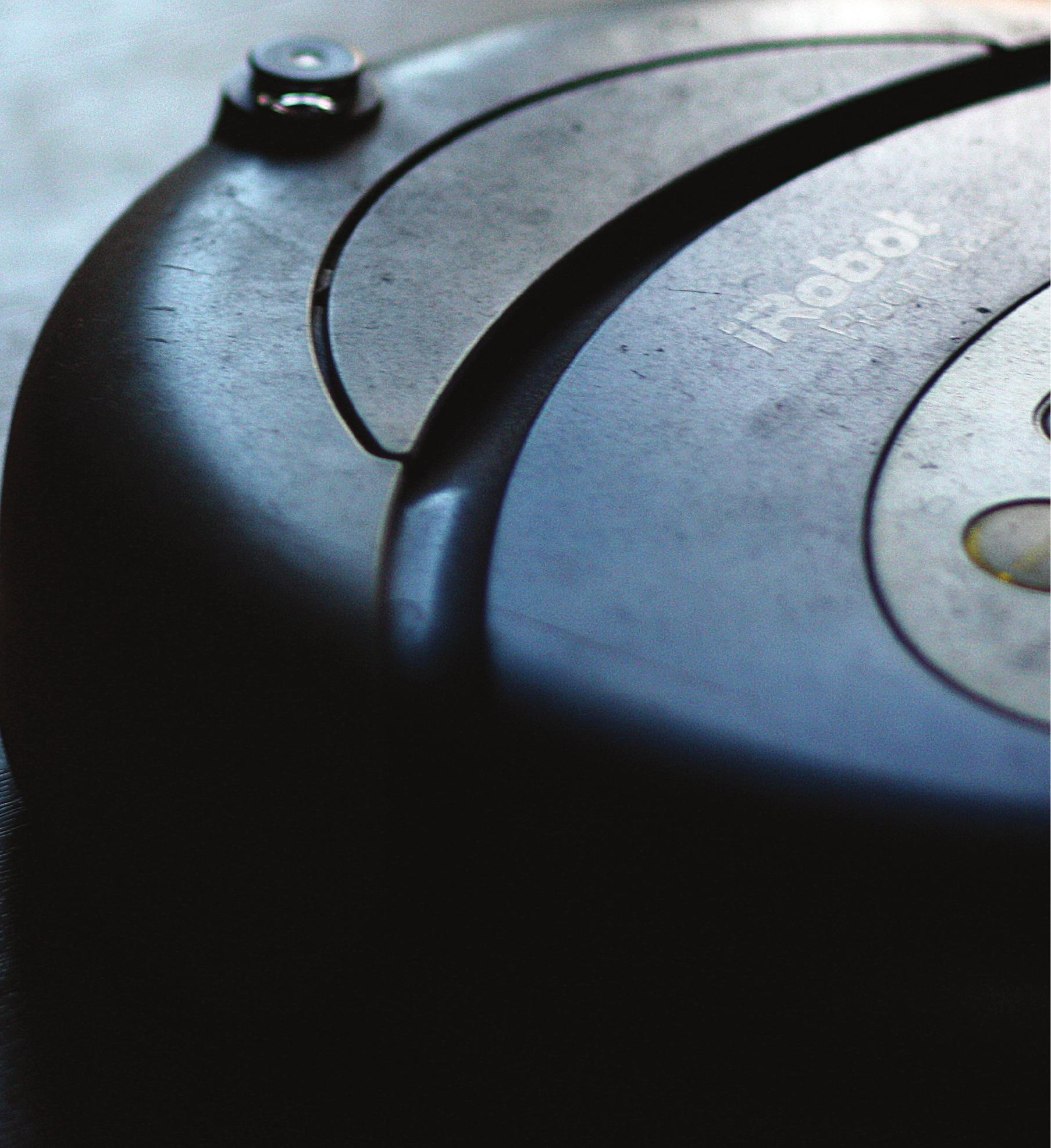




\title{
Will Your Household Adopt Your New Robot?
}

\author{
Valérie Bauwens \\ École Polytechnique Fédérale de Lausanne | valerie.bauwens@epfl.ch \\ Julia Fink \\ École Polytechnique Fédérale de Lausanne | julia.fink@epfl.ch
}

Domestic robots have slowly found their way into some of our homes and onto the shelves of major stores selling technical appliances. Who hasn't already seen or heard of robots that vacuum or mow the lawn? As researchers in robotics, we feel this growing commercial success is a great opportunity to learn about robot adoption processes. Leaving the marketing buzz and usual fantasies about robot invasions aside, we are curious to find out how robots are perceived by users. Are robots revolutionizing people's practices at home? Understanding the adoption of such robots is also central, as it helps to pinpoint crucial factors to be taken into account while designing new robots. Other questions we wish to consider include: What convinces people to adopt them? What stops people from adopting them? What features or concepts should be transferred to future robot generations?

To answer these questions, we conducted an ethnographic study that analyzed how people adopted or rejected a vacuum-cleaning robot in their homes [1]. We gave a popular commercially available robot (iRobot's Roomba) to nine house- holds and observed them over a period of six months [2].

We recruited households with and without children, pets, and gardens. We analyzed cleaning habits before Roomba. We then observed how they evolved from the moment we brought them the robot: at installation, after two weeks, and then two and four months after installation.

\section{Adoption Factors}

Two weeks after we brought Roomba to their homes, two households were on the verge of stopping using the robot (we called them "rejectors"), four were sporadically using it (the "skepticals"), and only three were completely convinced about it (the "aficionados") After two months this classification was still valid and remained so until the end of our trial.

What drove people to adopt or reject Roomba? We identified seven key factors (see Figure 1). According to our findings, the first two criteria (practical utility and physical space) are prerequisites to overcoming all the other adoption hurdles. It should be noted that under "normal commercial conditions," in which people would have had to pay for Roomba, economic utility might have been 
- Figure 1. Key adoption criteria per user groups.
Attitude 1: Rejectors

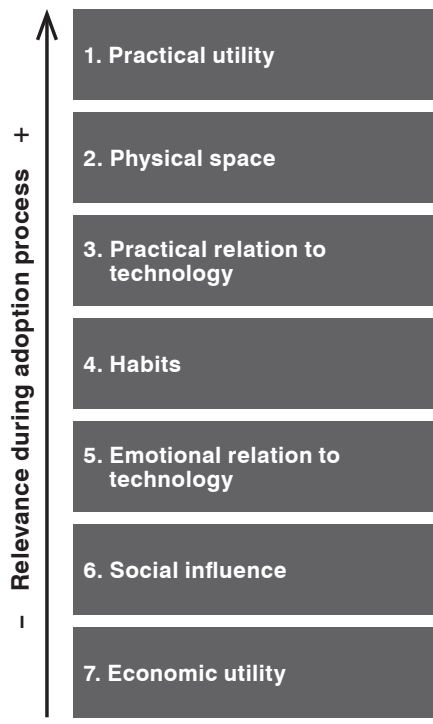
Roomba does not clean well enough; does not make me save time.
Attitude 2: Skepticals

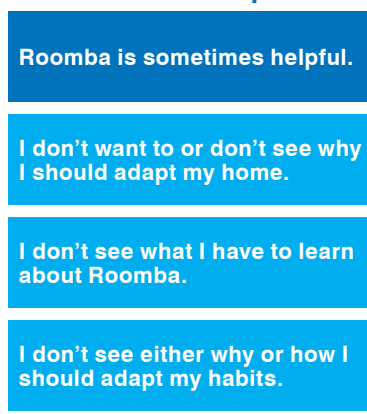

Attitude 3: Aficionados

I managed to get rid of some cleaning sessions.

I have adapted my furniture, cables, etc.

I have learned how to use the technology optimally.

I have understood how I have to adapt my habits.

Few personal interactions with Roomba. It has become less fun over time.

I showed Roomba to some friends.

What about costs of future spare parts?

one of the most important factors affecting adoption. Interestingly, the identified criteria match quite well with those identified in other studies on adoption of technology [3,4].

Factor 1: Practical utility. People agreed to participate in the study primarily because they thought they could spend less time vacuuming. Thanks to Roomba after two months, all three households that adopted the robot had managed to get rid of some cleaning tasks. One mother eliminated her three-times-daily use of the broom to clean under the kitchen table. Another mother managed to use her traditional vacuum only once a week instead of three to four times a week. A single man completely stopped using the traditional vacuum. For him, Roomba cleans well enough and solves all the other inconveniences related to vacuuming (e.g., previously he had tied the tubes of his traditional vacuum cleaner with a rope in order to store it neatly). In other words, these three households found that Roomba enabled a house as clean as before or cleaner, with less effort. In contrast, Roomba had not managed to solve any major pain point for the skepticals or the rejectors. A rejector said, "I clean faster and better than Roomba. I lose time when I'm using Roomba."

Factor 2: Physical space. All of our Roomba aficionados either had an optimal environment for Roomba to work or adapted their physical space to the robot to make it to work optimally. This phenomenon is called "Roombarization" [5]. A single man spent a whole Sunday afternoon securing his Wi-Fi access point to the wall in his living room so that Roomba would not get tangled up in cables on the floor. He also rearranged all the furniture in his living room. Roomba presented an opportunity to clean up his "cable salad" on the floor. Interestingly, when he uses Roomba he does not mind placing his coffee table on his couch to let Roomba vacuum optimally (see Figure 2).

None of the skepticals or rejectors had done anything similar. For instance, Roomba has difficul- ties climbing onto some rugs and carpets and tends to release some dust when doing so. One of our participants had a nice rug in her living room. Between her rug and a vacuum-cleaning robot that releases dust, the choice was easy to make.

Factor 3: Practical relationship to technology. Learning how to use Roomba was also an important aspect in adoption. All three aficionados had taken the time to learn how to use Roomba in an optimal way. One of the sporadic users might have optimized its use by making use of the infrared barriers, which would limit the areas in which Roomba worked. Unfortunately, she was not willing to learn how to use them. Another aspect mentioned by three of our participants is the control of the robot. A rejector said, "We don't trust it fully," complaining that Roomba appears to move around in an uncoordinated way. The three aficionados had learned to trust and cope with Roomba's surprising way of moving around.

Factor 4: Habits. All three aficionados have adapted their habits or 


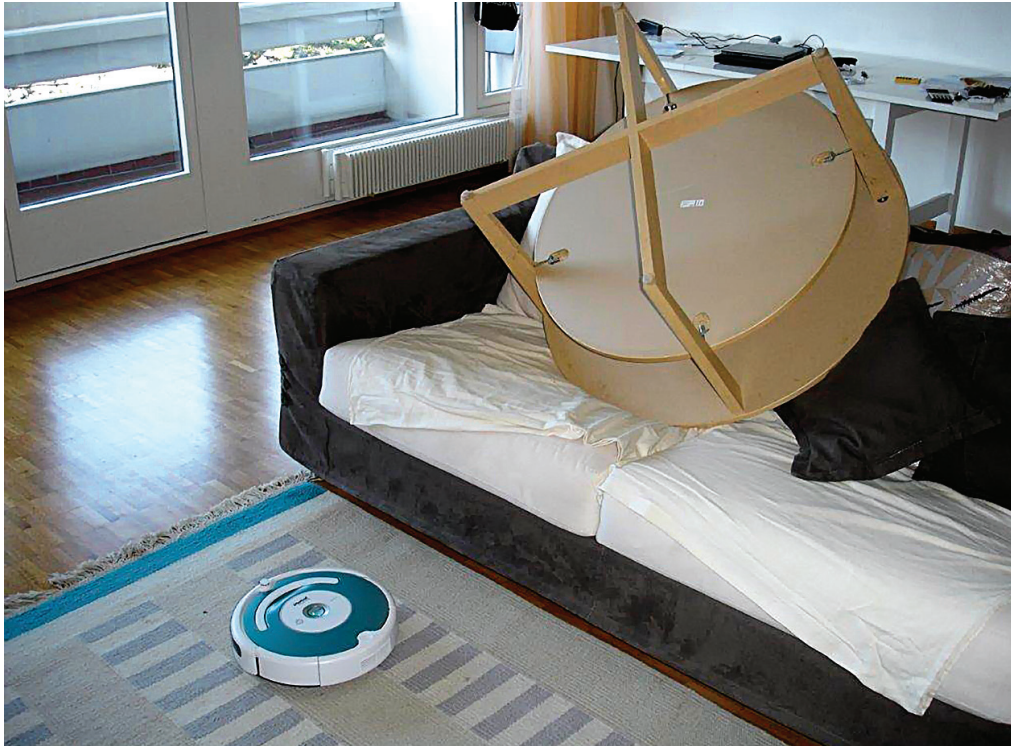

did not have to change their habits in order to use Roomba. One of our participants was fond of art and books. She had many statues she had sculpted herself on the floor, as well as piles of books. Other users liked eating in their living room and would leave trays on the floor with, for instance, marmalade on them. Why would they change their habits of reading from the piles of books on the floor or eating in their living room for a vacuum cleaner? Why would they give up the pleasure of being surrounded by art?

Factor 5: Emotional relationship to technology. Emotional relationship to technology can be summarized under two categories: hedonism and communicating with technology. In terms of hedonism, nearly all of our participants manifested enthusiasm when we brought them Roomba, especially children (e.g., one welcomed us wearing a T-shirt with a robot on it). In the first weeks of adoption, Roomba generated enthusiasm because of its erratic and surprising movements. One adult liked how Roomba would drive back into its docking station: "It looks like invented a laser game and a "robot show." Nevertheless, the enthusiasm faded quickly. Only a few younger children (up to five years old) went on playing with it. Pets were indifferent to Roomba or evolved over time from angry or afraid to indifferent. We did not observe the famous YouTube "Roomba cat stroll" (http://www.youtube.com/watch?v= ewdbilswjaM\&feature=related).

In terms of communication, we witnessed few "social interactions" with Roomba. One elderly lady gave a name to the robot, but her interactions remained purely functional. Another talked to it from time to time- "Go and do your work in the kitchen..."-but we could not observe lasting forms of emotional attachment. As with most of our participants, a nine-year-old boy it is just a vacuum cleaner."

Factor 6: Social influence. Many participants showed or even lent out Roomba to friends or colleagues, which implies that Roomba played a Star Wars spaceship." Some kids said, shrugging his shoulders, "Well, a socially positive role. One participant said, "It provides a subject of conversation at work with your colleagues or when you have guests at home." Another important point is that we did not encounter any negative prejudice toward robots. Roomba was often described as being "cute" and "friendly with its round shape." Within families themselves, household members influenced each other. For instance, in one family, on the first day the father had declared that a vacuum cleaner like Roomba would never perform as well as a classical vacuum: "It does not have as many watts." This family never really adopted Roomba. A quantitative analysis of our results confirmed that being part of a particular household influences how you perceive the robot [6].

Factor 7: Economic utility. We offered Roomba for free as a reward for participating in our research. The price was therefore not a barrier to entry. Nevertheless, as mentioned earlier, we believe that if people had to pay for Roomba, price could have been one of the main adoption hurdles (the average price is around $\$ 400)$. For example, one of our participants said, "I am not sure I would have paid that much. When you buy Miele, you know what you get." Establishing the brand as a quality brand is a challenge. One of our participants suggested that shops should enable potential buyers to try it out for a few days. Cost of replacement of spare parts and the longevity of the battery were also often mentioned as potential issues to consider when buying Roomba or even using it further.

Not a Revolution, but an Evolution Let's come back to the initial question: Are these vacuum-cleaning robots starting a revolution in our Figure 2.
"Roombarization"
while using
Roomba. 


\section{An Introduction} to Roomba

Roomba is a vacuum-cleaning robot sold by iRobot that moves around flat surfaces autonomously. It is programmed to optimally vacuum a place, with sensors that enable it to detect obstacles; for instance, it does not fall down stairs. It says a few sentences, such as "Roomba error 2" and "Please charge Roomba." The models used for our research all have a docking station where the Roomba goes back to recharge, three buttons (start; dock, to go back to the docking station; and spot, to vacuum around a precise spot), and some have virtual walls (infrared walls that force the robot to stay within a defined perimeter). To use it, one can push a button and then walk away. Roomba does not scratch any furniture. It does not break anything except very fragile objects in its path. Nevertheless, it is likely to get caught up in cables lying around.

households? At this stage, we believe one should talk about an evolution rather than a revolution. First, the domestic robots available today on the market are still used in few situations (e.g., cleaning gutters, mowing lawns, etc.). Second, according to our study, only a minority of households adopted Roomba. Indeed, it did not prove robustly adaptable to any kind of physical environment. Third, Roomba has not had a major impact on practices at home. Even though previous research indicated that Roomba would motivate people to renegotiate task responsibilities around cleaning [7, 8], we did not notice that; it simply enabled some participants to get rid of some vacuuming tasks.

\section{Lessons for Roomba's Designers}

Roomba proved to be an outstanding cleaning companion for some of our families. What convinced them was that they managed to reduce their cleaning efforts with few adaptation efforts (little to be learned, few modifications of their homes and habits). For the other households, Roomba still needed some design modifications. First, it was not usable across a wide variety of physical environments (e.g., houses with clutter on the floor or with thick carpets or door sills). Second, it needed to be more convincing in terms of reducing cleaning efforts (e.g., vacuuming faster while being less noisy) and increasing cleanliness (e.g., not releasing balls of dust, vacuuming well in corners). We believe that what could also increase adoption is more transparent communication of Roomba's capacities (e.g., how long it normally takes to vacuum how many square meters). People are not interested in knowing about Roomba's features but rather in how to optimally use it-for instance, how to use its virtual walls or whether or not to leave it to roam the house on its own.

\section{Lessons for Future Service Robots}

How can we transfer these lessons to future robots? Future domesticservice robots should definitely focus on enabling their users to quickly experience their usefulness, with low adaptation efforts. When it comes to solving the issue of the physical space, there are different paths to follow. Should Roomba really become an all-around vacuum cleaner, riding up stairs, dealing with books and thick carpets? Wouldn't a vacuum cleaner be more efficient if it were specialized? We have seen in our research that the cleaning pain points are often linked to specific spots in the house (e.g., the kitchen table, the entry hall). It also isn't clear what should be undertaken in terms of interactive capabilities. On the one hand, a robot that talks does, at first, raise enthusiasm. On the other hand, one of our participants said he did not want to have conversations with his vacuum cleaner. We believe that in order to answer these questions, an appropriate approach would be to do a comparative study of new generations of robots based on longitudinal ethnographic research. Good things come to those who are patient-and willing to give new technologies a try.

\section{ENDNOTES:}

1. This research is part of a wider nationally funded research program which ambitions to foster the introduction of robots in private environments (NCCR http://www.nccr-robotics.ch/).

2. According to Sung et al. [5,8], usage patterns of a Roomba settle after two months.

3. Venkatesh, V., Bala, H. Technology acceptance model 3 and a research agenda on interventions. Decision Sciences 39, 2 (2008).

4. Brown, S., Venkatesh, V. Model of adoption of technology in households: A baseline model test and extension incorporating household lifecycle. MIS quarterly 29, 3 (2005), 399-426.

5. Sung, J., Christensen, H.I., and Grinter, R.E. Robots in the wild: Understanding long-term use. Proc. HRI 2009.

6. Fink, J., Bauwens, V., Mubin, O., Kaplan, F., and Dillenbourg, P. People's perception of domestic robots: Same household, same opinion? Proc. ICSR 2011 (Amsterdam, The Netherlands), accepted for publication.

7. Forlizzi, J., DiSalvo, C. Service robots in the domestic environment: A study of the Roomba vacuum in the home. Proc. HRI 2006 (Salt Lake City, UT). ACM Press, New York, 2006, 258-265.

8. Sung, J., Grinter, R.E., and Christensen, H.I. Domestic robot ecology. An initial framework to unpack long-term acceptance of robots at home. Int J Soc Robot 2, 4 (2010), 417-429.

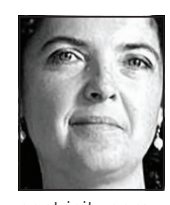

ABOUT THE AUTHORS Valérie Bauwens works in the CRAFT department at the École Polytechnique Fédérale de Lausanne (EPFL) studying the
Lalytechnique Federale de adoption of robots in homes. She is the founder of www. humancentricity.com, which specializes in ethnographic market research and teaching ethnography.

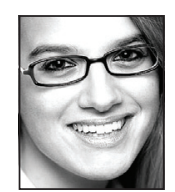

Julia Fink is a Ph.D. candidate in the CRAFT department at the École Polytechnique Fédérale de Lausanne (EPFL), studying human-robot interaction in domestic environments. She has a multidisciplinary background in media, technology, and communication. 